\title{
REDUCTION OF DYNAMIC IMPACTS IN BLOCK MADE OF CONCRETE - RUBBER COMPOSITES
}

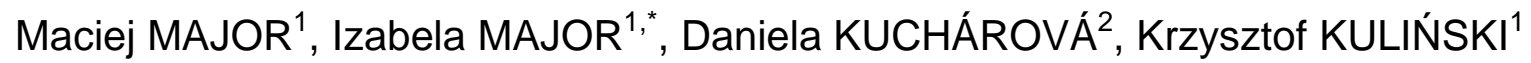 \\ ${ }^{1}$ Faculty of Civil Engineering, Czestochowa University of Technology, ul. Akademicka 3, 42-200 \\ Częstochowa, Poland. \\ ${ }^{2}$ Faculty of Civil Engineering, University of Žilina, Univerzitná 8215/1, 01026 Žilina, Slovakia. \\ corresponding author: imajor@bud.pcz.czest.pl.
}

\begin{abstract}
The paper presents numerical analysis of block made of three layers: concrete with I-shape rubber pads, space filled with air and concrete with embedded cross rubber pads, respectively. The block is subjected to the dynamic load. To the analysis as rubber the hyperelastic incompressible Zahorski material model was assumed. This material well describes the real material properties in the range of large elastic deformations. Embedded rubber pads provide an additional protection against the transversal dynamic load. ADINA software was utilized to perform numerical analysis of determining the percentage damping factor of rubber-concrete composite in comparison with block made of concrete.
\end{abstract}

\section{Keywords:}

Composite;

Concrete;

Rubber;

Zahorski material;

Impact.

\section{Introduction}

From the centuries the wave phenomenon due to its influence on surrounding environment has been studied by many researchers. Both classical mathematical formulation and finite element method approach are used to describe wave propagation in different materials and fluids. From the engineering point of view, in civil engineering wave propagation in materials or structures should be strongly avoided. Waves with frequency similar to the structure natural frequency may lead to the resonance, which furtherly may result in construction failure or even destruction. Recently, there are many known materials which help reduce dynamic and acoustic effects like polyurethane, styrofoam, mineral wool, rubber, etc. Mechanical properties of mentioned materials exclude them from utilizing in structures where significant in and out of plane forces are transferred. As a solution concrete blocks with special holes specially prepared at the technological process under rubber pads fulfilment are proposed.

It is believed that the precursors of experimental studies on rubber material to mathematically determine its behavior under applied external loads were Mooney and Rivlin [1, 2]. Authors established the mathematical model which took into considerations the applied loading, in the '40s and '50s of the former century. In consecutive years it has been proved that mathematical description of rubber behavior presented by Mooney-Rivlin may be safely utilized for cases where applied tensile or compressible force does not lead to displacements exceeding the $\lambda=1.4$ of original object dimension in the direction of acting force. In further years Zahorski $[3,4]$ have continued studies of former authors and modified the Mooney-Rivlin mathematical model, allowing thereby consideration of higher values of external loading, widening the range of displacements up to $\lambda=3$. Kosiński [5] studied the evolution and reflection of particular shock waves in selected rubber materials as well as carried out research of disturbance wave propagation in layered-composite materials, widely described in [6].

In the late '90s due to the rapid technological development, increasingly easier access to computers and development of finite element based software many institutions carried out numerical research. According to that analyses of many materials/structures without the necessity of performing expensive experimental tests could be performed. FEM not only allow reduce costs of performed analyses, it is also more environmental friendly than research performed on the real or scaled object and in many cases allow to obtain interesting results much faster than traditional methods (comp. [7]). Moreover, via the numerical approach arisen tens of papers concerning research on the rubber 
materials (e.g. [8 - 11]) and thousands of papers, concerning problems from also other areas of life. Examples of construction and its components numerical research may be found in [12 - 14].

In this paper percentage damping of disturbance wave propagation is determined through the numerical calculations in selected regions of three-layered wall made of concrete-rubber composites in relation to same wall made of concrete blocks. Cross-section of three-layered wall beginning from the outside is: small concrete blocks with rectangular shape rubber pads, empty space filled with air and larger concrete blocks with rubber pads in shape of crosses, respectively. Wave propagation is a result of applied dynamic concentrated force perpendicularly to the rubber pads insertion direction. Mentioned force is applied in the most undesirable area, i.e. in the central point of frontal wall mortar layer, which connects the composite blocks. For the numerical calculations purposes finite element method based software - ADINA program was chosen.

\section{Hyperelastic materials}

\subsection{Basic information about hyperelastic materials}

Particular materials behaviour under the influence of different external factors may be described via constitutive equations (comp. [15]). Constitutive equation concerning any isotropic elastic body may be presented as:

$W=W\left(I_{1}, I_{2}, I_{3}\right)$,

where by $I_{1}, I_{2}, I_{3}$ the deformation tensor invariants are denoted.

Considering the elastic body, which have imposed internal bonds one should be noticed that it cannot be subjected to any deformation, while elastic body without internal bonds may be freely subjected to any deformation. Incompressibility is the fundamental principle of internal bonds; isochoric deformations are only acceptable, which do not change the body volume. According to that permissible deformation condition may be written as $I_{3}=1$. Mentioned condition causes that the $I_{3}$ invariant argument is omitted in the deformation energy function. Hence two other invariants are passed as arguments to the function, and in analogy to the condition presented in Eq. 1 one can be written:

$$
W=W\left(I_{1}, I_{2}\right) .
$$

Incompressible material constitutive relations are defined through the invariant $I_{3}=1$ and expression presented in Eq. 2. Non-linear theory of elasticity for each considered problem imposes a new definition of constitutive relationship. It is worth noting that for large deformations, generalized constitutive equation concerning rubber-like material does not exist cause each material behaves in different specific manner. Hence, it is necessary to determine by an experimental procedure, for each individual case, a constitutive equation for considered model.

\subsection{Hyperelastic incompressible rubber - Zahorski description}

The constitutive relationship defining hyperelastic and incompressible Zahorski material may be expressed as:

$W\left(I_{1}, I_{2}\right)=C_{1}\left(I_{1}-3\right)+C_{2}\left(I_{2}-3\right)+C_{3}\left(I_{1}^{2}-9\right)$,

where via $C_{1}, C_{2}, C_{3}$ parameters are defined material constants.

For describing a medium subjected to various external factors constitutive equations are being used. Selection of appropriate material model strictly depends on factors, which have the most significant influence of selected material behaviour. According to relationship presented in Eq. 3 one can notice that Zahorski material non-linearly depends on deformation tensor invariants. Discussed condition was considered in cases of disturbance propagation research held in [5, 9]. Proposed by Zahorski new constitutive relationship allows to perform more complete analysis of mechanical wave propagation than via equations proposed by Mooney-Rivlin. 
The non-linear term $C_{3}\left(I_{1}{ }^{2}-9\right)$ presented in Eq. 3 shows its significant advantage when it comes to wave propagation studies. Through this term more comprehensive analysis can be performed and solution quality is improved. Mooney-Rivlin material model can be obtained if zero value is introduced into constant $C_{3}$. Such case is frequently used for rubber and rubber-like materials analyses.

Stress-strain functions for both: Mooney-Rivlin and Zahorski material generated under the ADINA software are presented in Fig. 1. In order to present Zahorski material, modifications to the material libraries in ADINA program $[15,16]$ had to be introduced.
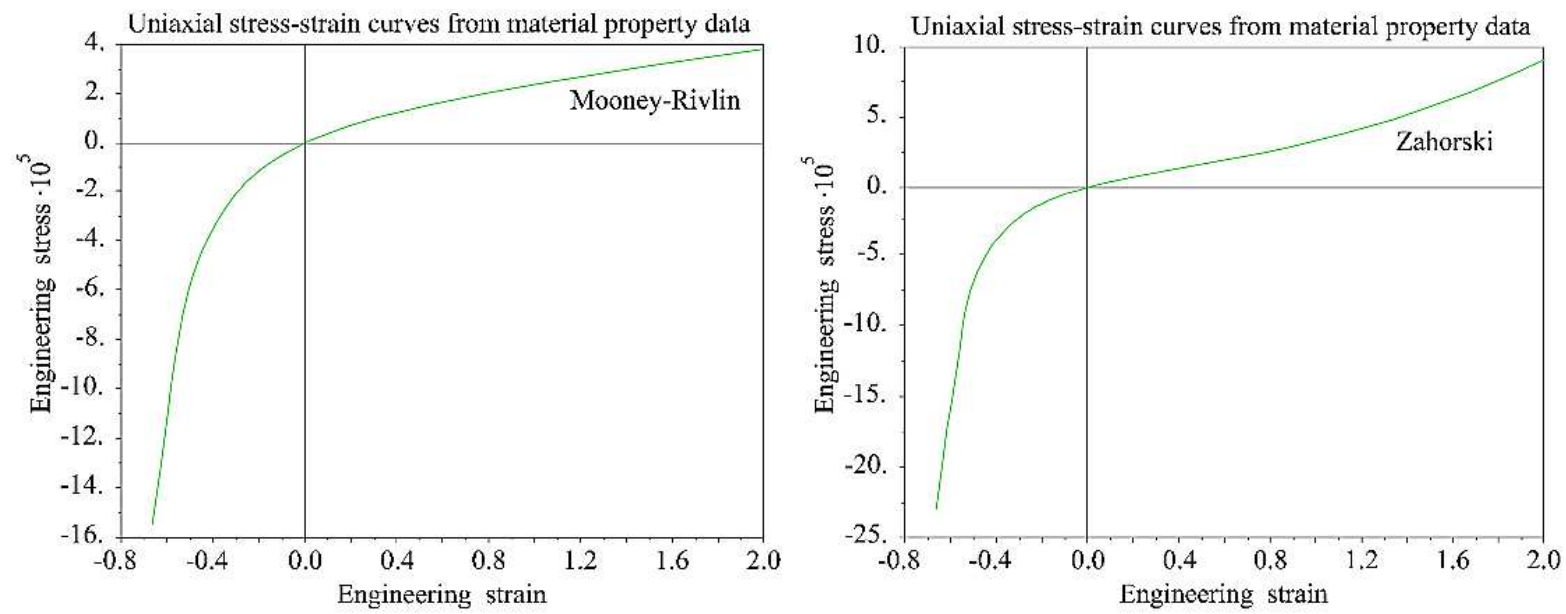

Fig. 1: Stress - strain diagram for analysed rubber. a) Mooney - Rivlin material, b) Zahorski material.

In this paper following rubber material constants are used in order to describe Zahorski material: $C_{1}=62780 \mathrm{~Pa}, C_{2}=8829 \mathrm{~Pa}$, and $C_{3}=6867 \mathrm{~Pa}$. Mentioned values, transformed to the SI system are based on those presented in [3]. In the Table 1 strength parameters for analysed rubber are presented (see [3]).

Table 1: Analysed rubber strength parameters.

\begin{tabular}{|l|c|c|}
\hline \multicolumn{1}{|c|}{ Name } & Value & Unit \\
\hline Vulcanization time at. $143^{\circ} \mathrm{C}$ & 5 & $\mathrm{~min}$ \\
\hline Strength at elongation of $500 \mathrm{~mm} / \mathrm{min}$ & $\sim 3.01 \cdot 10^{4}$ & $\mathrm{kN} / \mathrm{m}^{2}$ \\
\hline Strength at elongation of $5 \mathrm{~mm} / \mathrm{min}$ & $\sim 1.05 \cdot 10^{4}$ & $\mathrm{kN} / \mathrm{m}^{2}$ \\
\hline Elongation at $5 \mathrm{~mm} / \mathrm{min}$ & $\sim 5.81 \cdot 10^{2}$ & $\%$ \\
\hline
\end{tabular}

\section{Numerical model details}

For the numerical analysis purposes, section of the three-layered wall model containing only one row of composite/solid blocks in the vertical planar plane direction was adopted. Following dimensions were used for three-layered wall section: total length of $1.01 \mathrm{~m}$, total width of $0.405 \mathrm{~m}$, and total height of $0.25 \mathrm{~m}$, respectively. Dimensions of composite blocks with rubber insertion pads are presented in Fig. 2, whereas whole numerical model was presented in Fig. 3. 


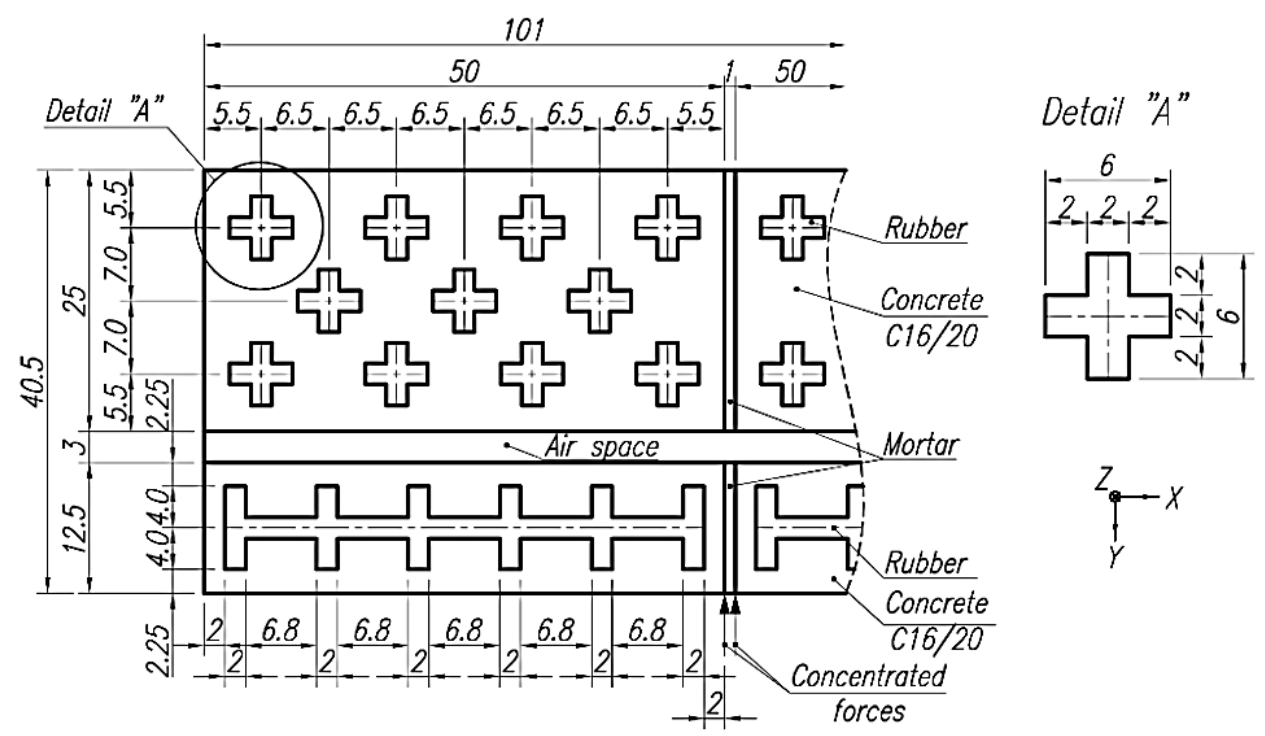

Fig. 2: Scheme of the analyzed three-layered wall $-X Y$ plane view.

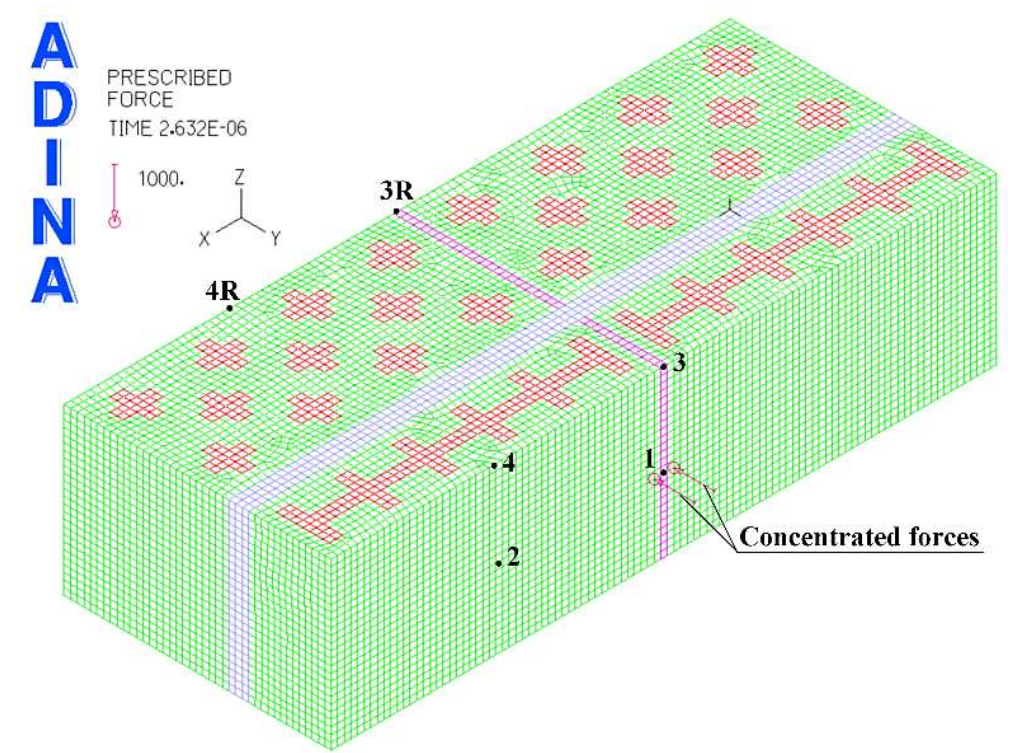

Fig. 3: Numerical model of the three-layered wall subjected to the dynamic concentrated forces located near the mortar with presented misses stress measurement points locations (1 - 4).

According to the Fig. 2 placement of the concentrated forces was assumed as the most unfavorable, i.e. at the point of contact between concrete block and mortar. Mentioned force was placed at the midpoint between top and bottom planar surface of the wall section. It is worth noting that the rubber pads have exactly the same height as the concrete block - equal $25 \mathrm{~cm}$. Moreover, concentrated forces reach their maximum value of $1000 \mathrm{~N}$ at $2.632 \cdot 10^{-6} \mathrm{~s}$ from the start of analysis and afterwards force value is set to 0 till end of analysis. Mentioned force application leads to disturbance wave propagation. In this paper both names, i.e. disturbance wave propagation and mechanical wave propagation due to the same phenomenon description are used interchangeably. Due to the fact that the energy from the prescribed forces was transferred through the model it could be possible to observe the propagation via the Misses stress plot. Presented in Fig. 3 are dots with numbers from 1 to 4 represents measurement points of Misses stress. Moreover, on the rear wall side reflection of frontal points with additional $\mathrm{R}$ letter suffix were adopted. The Misses stress was read-out as an averaged value from adjacent elements close to the black dots presented in Fig. 3 . In order to simplify the analysis only one vertical layer of blocks with the air space between them was studied. Three different time steps were chosen in order to compare the stress obtained in the wall made of composite blocks in regard to the blocks made only of concrete, i.e. the moment of reaching the maximum value of the forces at $2.632 \cdot 10^{-6} \mathrm{~s}, 6.842 \cdot 10^{-5} \mathrm{~s}$, and $1.316 \cdot 10^{-4} \mathrm{~s}$, respectively. 
In presented numerical model in Fig. 3, boundary conditions with respect to presented coordinate system are: both external side $Y Z$ planes had $X$ - and $Y$-axis displacement direction fixed, whereas top and bottom $X Y$ planes of the wall section had all displacement directions and $Y$-, $Z$-axis rotation fixed. Blocks are described with C16/20 concrete grade, mortars have $4 \mathrm{MPa}$ compressive strength, air has constant temperature of $20^{\circ} \mathrm{C}$ whereas rubber have properties described via the material constants presented in Table 1. Following ADINA material models were used to represent these materials: both concrete blocks and mortars were described via "Concrete" material model, rubber pads via the "Mooney-Rivlin" module (modified by Major [16] in order to obtain Zahorski material model) with density of $1190 \mathrm{~kg} / \mathrm{m}^{3}$ and air as a "Potential based fluid" with bulk modulus 101 $\mathrm{kPa}$ and density $1.20 \mathrm{~kg} / \mathrm{m}^{3}$.

Considered three-layered wall was meshed with the use of "3D-Solid" 8-node hexahedrons finite elements. Single element mesh size was assumed to be around $\sim 0.01 \mathrm{~m}$. Exactly the same model mesh was used to perform the analysis of solid concrete wall, whereas rubber material description was replaced with the concrete C16/20 grade class. Complete model contained 115333 nodes and 148260 finite elements.

\section{Numerical results}

Knowing that energy is transferred through the mechanical waves, for each time step the wave propagation could be clearly observed through Misses stress distribution plot. Considered in this paper Misses stress values were read-out from four points $(1-4)$ located on the front surface of the threelayered wall and points $(1 R-4 R)$ located on the rear wall surface, which were the exact frontal points reflection. Three different time steps were chosen, i.e. $2.632 \cdot 10^{-6} \mathrm{~s}, 6.842 \cdot 10^{-5} \mathrm{~s}$, and $1.316 \cdot 10^{-4} \mathrm{~s}$, respectively. Misses stress results for each adopted measurement point were tabulated in Table 2.

Table 2: Misses stress results at measurement points located on three-layered wall made of composite blocks and concrete blocks for $t=2.632 \cdot 10^{-6} \mathrm{~s}, 6.842 \cdot 10^{-5} \mathrm{~s}$, and $1.316 \cdot 10^{-4} \mathrm{~s}$.

\begin{tabular}{|c|c|c|c|c|c|c|}
\hline \multirow{3}{*}{ 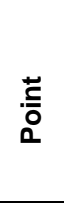 } & \multicolumn{6}{|c|}{ Misses stress $[\mathrm{Pa}]$} \\
\hline & \multicolumn{3}{|c|}{ Composite wall (Zahorski) } & \multicolumn{3}{|c|}{ Solid concrete block } \\
\hline & $\begin{array}{c}t=2.632 \cdot 10^{-6} \\
{[\mathrm{~s}]}\end{array}$ & $\begin{array}{c}t=6.842 \cdot 10^{-5} \\
{[\mathrm{~s}]}\end{array}$ & $\begin{array}{c}t=1.316 \cdot 10^{-4} \\
{[\mathrm{~s}]}\end{array}$ & $\begin{array}{c}t=2.632 \cdot 10^{-6} \\
{[\mathrm{~s}]}\end{array}$ & $\begin{array}{c}t=6.842 \cdot 10^{-5} \\
{[\mathrm{~s}]}\end{array}$ & $\begin{array}{c}t=1.316 \cdot 10^{-4} \\
{[\mathrm{~s}]}\end{array}$ \\
\hline 1 & 71009.90 & 288864.00 & 342573.00 & 71044.90 & 199417.00 & 187217.00 \\
\hline 1R & 0.00 & 0.65 & 6473.53 & 0.00 & 132.05 & 8215.13 \\
\hline 2 & 0.00 & 3573.67 & 31630.70 & 0.00 & 3125.10 & 50290.60 \\
\hline $2 R$ & 0.00 & 0.00 & 1020.69 & 0.00 & 0.01 & 2455.81 \\
\hline 3 & 0.01 & 134777.00 & 137568.00 & 0.01 & 144317.00 & 85380.50 \\
\hline $3 \mathbf{R}$ & 0.00 & 0.02 & 4526.07 & 0.00 & 0.06 & 6102.36 \\
\hline 4 & 0.00 & 1552.97 & 3158.72 & 0.00 & 2292.05 & 76232.70 \\
\hline 4R & 0.00 & 0.00 & 894.01 & 0.00 & 0.00 & 2305.56 \\
\hline
\end{tabular}

Taking into consideration values of Misses stress presented in Table 2, one can state that stress is slightly lower at point "1" in the composite three-layered wall in comparing with solid concrete wall at $t=2.632 \cdot 10^{-6} \mathrm{~s}$, which is connected with the wall rigidity. Composite blocks with rubber insertion pads have lower rigidity in comparison to the solid concrete blocks due to the rubber material, which has significantly lower rigidity in comparison to the concrete material. Hence energy transferred from the point with subjected concentrated force in case of composite block is slightly more dissipated through the structure deformation. In the same point "1" in presented consecutive time steps $\left(t=6.842 \cdot 10^{-5} \mathrm{~s}\right.$ and $\left.t=1.316 \cdot 10^{-4} \mathrm{~s}\right)$ mechanical energy is greater than in the composite blocks wall, which is connected with the wave interference phenomenon. Travelling waves are refracted and even reflected when the wave head meets the rubber insert pad, however some of the energy is absorbed via the rubber material. In point " 2 " at $t=6.842 \cdot 10^{-5} \mathrm{~s}$ interference phenomenon may also be observed, while at $t=1.316 \cdot 10^{-4} \mathrm{~s}$ one may notice that in composites some of the energy was absorbed via rubber pads in comparison to the solid concrete block. Point "3" indicate that at $t=6.842 \cdot 10^{-5} \mathrm{~s}$ some of the energy was absorbed via both the composite deformation and rubber pads, whereas at $t=1.316 \cdot 10^{-4} \mathrm{~s}$ wave interference had occurred. At point " 4 ", which is located the 
farthest from the applied load, one can observe that the rubber pads significantly damp the wave propagation in regard to the solid concrete blocks. In this case damping is provided via the rubber insert introduced in $X$ - and $Y$-axis directions. Stress distribution plot for the impact load at $t=1.316 \cdot 10^{-4} \mathrm{~s}$ in the " $X Y$ " cutting plane through points 1 and 2 is presented in Fig. 4 . Scale of the stress plot had been limited to $20000 \mathrm{~Pa}$ in order to obtain better clearance of propagating mechanical wave, whereas blank strip denotes the air layer in the wall section.

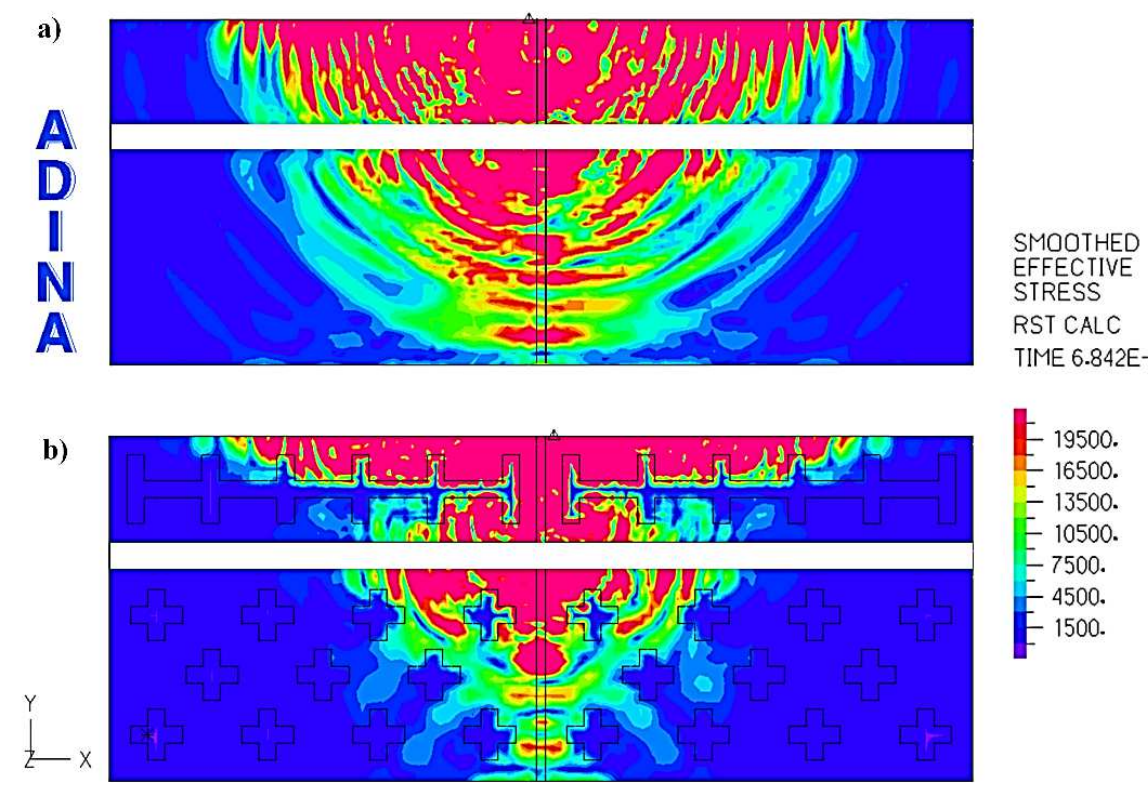

Fig. 4: Stress distribution representing disturbance wave propagation in solid bodies cut via horizontal plane passing through points 1 and 2 for $t=1.316 \cdot 10^{-4} \mathrm{~s}$. a) Concrete blocks, b) Concrete-rubber composites.

On the basis of Fig. 4 one can state that the head of mechanical wave passing through solid concrete blocks (see Fig. 4a) was almost undisturbed and have circular shape, whereas head of the mechanical wave in composite blocks transfers less energy and is far more disturbed via the rubber inserts (see Fig. 4b). In case of composite blocks, energy is mainly transferred through the rigid body of the block, which is clearly visible in Fig. 4b. In Fig. 5 percentage damping of disturbance wave propagation on the rear side of the wall in measurement points $1 R-4 R$ was presented.

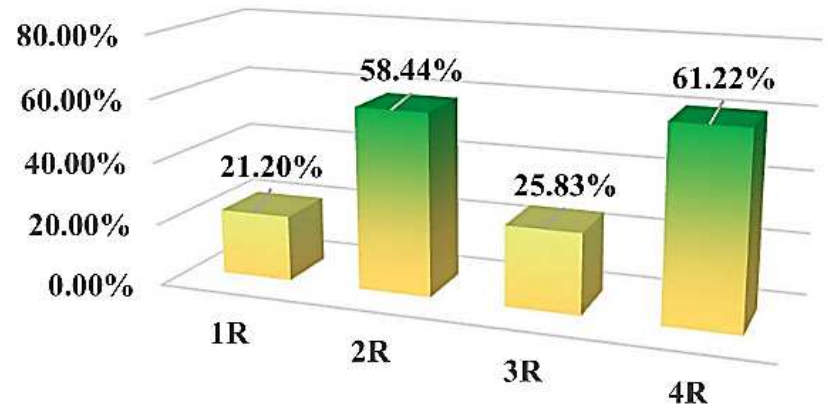

Fig. 5: Percentage damping of disturbance wave on inner three-layered composite wall side for adopted measurement points in comparison to concrete blocks. Time $t=1.316 \cdot 10^{-4} \mathrm{~s}$.

According to the Fig. 5 one can state that the longer distance from applied load point and the more layers of rubber were encountered by mechanical wave head, the more significant percentage damping could be observed (compare point "1" and "4" from Fig. 6).

\section{Conclusion}

In this study dynamic numerical analysis with the use of finite element method software in order to estimate damping of disturbance wave propagation in section of composite three-layered wall 
subjected to the impact load was presented. Through the analysis it was shown that the longer distance from the applied loading and the more layers of rubber encountered via mechanical wave head, the higher percentage damping can be achieved. In discussed section of the wall, on the opposite side from the applied load percentage damping varied from 21 up to $61 \%$ in regard to the three-layered wall only made of concrete.

On the basis of performed analysis, presented blocks may be treated as a barrier from the external sources of vibration in constructions. Moreover, due to relatively small area of bored holes in comparison to the horizontal cross-section of larger and smaller blocks, holes arrangement, compressive strength of discussed blocks was only slightly reduced. It is worth noting that presented solution may be treated as innovative, due to low cost of implementation in technological process, materials which can be easily recycled and shape of the blocks, which allow avoid accidental incorrect assemblage. Despite many advantages, experimental studies should have also been performed to determine mechanical properties of presented solution.

\section{Acknowledgement}

This work was supported by the Grant National Agency VEGA of the Slovak Republic, project No. $1 / 0005 / 16$.

\section{References}

[1] MOONEY, M.: A theory of large deformations. J. Appl. Phys. Vol. 11, 1940, pp. 582 - 592.

[2] RIVLIN, R. S. - SAUNDERS, D. W.: Large elastic deformations of isotropic materials VII. Experiments of the deformation of rubber. Phil. Trans. Roy. Soc. A., Vol. 243, 1951, pp. 251 288.

[3] ZAHORSKI, S.: A form of elastic potential for rubber-like materials. Archives of Mechanics, Vol. 5, 1959, pp. $613-617$.

[4] ZAHORSKI, S.: Experimental tests of some rubber mechanical properties. Rozprawy inżynierskie Vol. 10, Iss. 1, 1962, pp. 193 - 207 (in Polish).

[5] KOSIŃSKI, S.: Reflection and evolution of an impact wave in selected hyperelastic materials. Wydawnictwo IPPT PAN, Warszawa, 1995 (in Polish).

[6] KOSIŃSKI, S.: Elastic waves in rubber-like layered composites. Wydawnictwo Politechniki Łódzkiej, Łódź, 2007 (in Polish).

[7] KORMANIKOVA, E. - KOTRASOVÁ, K.: Finite Element Analysis of Damage Modelling of Fiber Reinforced Laminate Plate. Applied Mechanics and Materials, Vol. 617, 2014, pp. 247 - 250.

[8] MAJOR, I. - MAJOR, M.: Travelling waves in a thin layer composed of nonlinear hyperelastic Zahorski material. J. Theoretical and Appl. Mechanics, Vol. 47, Iss. 1, 2009, pp. $109-126$.

[9] MAJOR, I. - MAJOR, M.: Comparative analysis of the distribution of effective stress in Mooney and Zahorski materials using ADINA software. Adv. Mat. Research, Vol. 1020, 2014, pp. 165 - 170.

[10] CIPOLATTI, R. - I-SHIH, L. - RINCON, M. A.: Mathematical analysis of successive linear approximation for Mooney-Rivlin material model in finite elasticity. J. Appl. Analysis and Computation, Vol. 2, Iss. 4, 2012, pp. 363 - 379.

[11] I-SHIH, L.: A note on the Mooney-Rivlin material model. Continuum Mechanics and Thermodynamics, Vol. 24, Iss. 4 - 6, 2012, pp. 583 - 590.

[12] MELCER, J.: A vehicle bridge interaction. Communications - Scientific Letters of the University of Zilina, Vol. 9, Iss. 3, 2007, pp. 5 - 10.

[13] VICAN, J. - KOTES, P. - SPIEWAK, A. - ULEWICZ, M.: Durability of bridge structural elements. Communications - Scientific Letters of the University of Zilina, Vol. 18, Iss. 4, 2016, pp. 61 - 67.

[14] KREJSA, M. - BROZOVSKY, J. - MIKOLASEK, D. - PARENICA, P. - FLODR, J. - MATERNA, A. - HALAMA, R. - KOZAK, J.: Numerical modelling of steel fillet welded joint. Advances in Engineering Software, Vol. 117, 2018, pp. 59 - 69.

[15] MAJOR, M. - MAJOR, I.: Modelling of wave phenomena in the Zahorski material based on modified library for ADINA software. Applied Mathematical Modelling, Vol. 46, 2017, pp. 727 735.

[16] MAJOR, M.: Modelowanie zjawisk falowych w hipersprężystym materiale Zahorskiego. Wydawnictwo Politechniki Częstochowskiej, Częstochowa, 2013 (in Polish). 